\title{
Produção de massa seca, volume radicular e eficiência nutricional de fósforo em Brachiaria brizantha cv. Marandu e Massai (Panicum maximum $\mathbf{x}$. infestum)
}

\author{
Production of dry mass, root volume and nutritional efficiency of phosphorus in Brachiaria \\ brizantha cv. Marandu and Massai (Panicum maximum x P. infestum)
}

Andre Luis Sodré Fernandes

Engenheiro Agrônomo (IFMT)

Discente IFMT Campus Confresa

E-mail: andreluizsodre@hotmail.com

Elizeu Luiz Brachtvogel

Doutor em Agronomia (UNESP)

Professor IFMT Campus Confresa

E-mail: elizeu.brachtvogel@cfs.ifmt.edu.br

\author{
Luis Lessi dos Reis \\ Doutor em Agronomia (UNESP) \\ Professor IFSULDEMINAS Campus Machado \\ E-mail: $\underline{\text { luis.reis@ifsuldeminas.edu.br }}$
}

Resumo: Avaliação de respostas das espécies forrageiras Brachiaria brizantha cv. Marandu e Massai (Panicum maximum xP. infestum) a diferentes doses de fósforo. $\mathrm{O}$ ensaio foi conduzido em casa de vegetação no IFMT - Campus Confresa, implantado em vasos plásticos de $5 \mathrm{dm}^{-3}$ com areia grossa lavada. Após sete dias da emergência foram selecionadas cinco plantas por unidade experimental. O delineamento experimental em blocos casualizados, combinados em esquema fatorial $5 \times 2$, totalizando 10 tratamentos com quatro repetições para cada época de coleta (30 e 60 dias após emergência). Os tratamentos consistiram em aplicações de doses de fósforo $(\mathrm{P})$, via solução nutritiva, correspondentes $0 \%, 25 \%, 50 \%, 75 \%$ e $100 \%$ da concentração de $\mathrm{P}$ em solução, que equivale a $0,0 \mathrm{mg} \mathrm{dm}^{-3} 36,9 \mathrm{mg} \mathrm{dm}^{-3}, 73,8 \mathrm{mg} \mathrm{dm}^{-3}, 110,8$ $\mathrm{mg} \mathrm{dm}{ }^{-3} 147,6 \mathrm{mg} \mathrm{dm}^{-3}$ respectivamente. O material vegetal coletado foi acondicionado em sacos de papel e levado a estufa de circulação de ar, forçado à $65^{\circ} \mathrm{C}$ até peso constante, para determinação de massa seca. As plantas foram moídas separadamente (parte aérea e raiz) para a determinação da concentração de fósforo. Os dados foram submetidos à análise de variância a nível de 5\% de probabilidade pelo teste F usando o software Sisvar. Observando-se efeito significativo para dose, espécie e interação entre os fatores (doses e espécie). Os resultados obtidos, foram em condições controladas, a espécie Brachiaria revelou-se ser mais eficiente na absorção e transporte do nutriente $\mathrm{P}$ do que a espécie Massai, consequentemente, alcançando maior produção de massa seca e raiz, evidenciando ser mais responsiva a adubação fosfatada.

Palavras-chave: Absorção; transporte; utilização.

Abstract: Evaluation of responses of forage species Brachiaria brizantha cv. Marandu and Massai (Panicum maximum x P. infestum) at different doses of phosphorus. The assay was conducted in a greenhouse at the IFMT - Confresa Campus, implanted in $5 \mathrm{dm}^{-3}$ plastic vats with washed coarse sand. After seven days of emergence, five plants per experimental unit were selected. The experimental design was a randomized block design, combined in a $5 \times 2$ factorial scheme, totaling 10 treatments with four replicates for each collection period (30 and 60 days after emergence). The treatments consisted of $0,25,50,75$ and $100 \%$ of the concentration of $\mathrm{P}$ in solution, corresponding to $0.0 \mathrm{mg} \mathrm{dm}-3 ., 9 \mathrm{mg} \mathrm{dm}-3,73.8 \mathrm{mg} \mathrm{dm}-3,110.8 \mathrm{mg} \mathrm{dm}-3,147.6$ $\mathrm{mg} \mathrm{dm}-3$ respectively. The collected vegetal material was conditioned in paper bags and taken to air circulating greenhouse, forced to $65^{\circ} \mathrm{C}$ until constant weight, to determine dry mass. The 
plants were ground separately (shoot and root) for determination of phosphorus concentration. The data were submitted to analysis of variance at a $5 \%$ probability level by the $\mathrm{F}$ test using the Sisvar software. Significant effect was observed for dose, species and interaction between the factors (doses and species). The obtained results were under controlled conditions, the Brachiaria species proved to be more efficient in the absorption and transport of the nutrient $\mathrm{P}$ than the Massai species, consequently, reaching higher dry mass and root yield, proving to be more responsive phosphate fertilization.

Keywords: absorption; transport; use.

\section{Introdução}

No Brasil, a produção pecuária é predominantemente extensiva sobre pastagens nativas ou cultivadas. Os índices zootécnicos da pecuária brasileira são baixos em razão, dentre outros fatores, da baixa qualidade e, principalmente, da pequena capacidade de suporte das pastagens (SANTOS et al. 2002). Ainda segundo o mesmo autor a baixa produtividade das pastagens ou a sua diminuição com o passar dos anos após o estabelecimento em solos tropicais, tem como causas principais: (a) a elevada acidez do solo $(\mathrm{pH}<5,0)$, a toxidez de alumínio e manganês e a baixa disponibilidade de nutrientes, principalmente de fósforo e de nitrogênio (RAO et al. 1995 apud SANTOS et al. 2002 ); (b) o caráter extrativista com que se pratica a pecuária, ignorando-se a retirada de nutrientes do solo via produção animal (ZIMMER e CORREA 1993), e (c) o inadequado manejo das pastagens (MACEDO, 1995).

Segundo Santos et al. (2002), o elemento fósforo tem uma atuação de grande importância no crescimento do sistema radicular, bem como no perfilhamento das gramíneas que são fatores primordiais para a maior produção das forrageiras. Embora o elemento fósforo, que de acordo com Holford (1997), depois do nitrogênio seja o segundo nutriente essencial mais limitante à produção agrícola nos solos tropicais, a "construção" da fertilidade do solo em fósforo torna-se particularmente importante, uma vez que esses solos apresentam baixa disponibilidade natural e alta capacidade de adsorção e de fixação desse nutriente. Somado a esses fatos, a absorção, assimilação e translocação de nitrogênio nas plantas podem ser restringidas pela deficiência de fósforo (GNIAZDOWSKA et al. 1999). Esses apontamentos mostram que a adubação fosfatada é imprescindível à implantação e manutenção das gramíneas; no entanto, são necessários a criação de critérios mais exatos para sua recomendação, visando a uma maior eficiência econômica da pecuária. (SANTOS et al. 2002)

A determinação dos níveis críticos de fósforo no solo e na planta é necessária para o estabelecimento das doses de fósforo a serem aplicadas e a avaliação do estado nutricional das plantas. Esses níveis críticos variam com as espécies, condições edafoclimáticas (temperatura, luminosidade, disponibilidade hídrica, tipo de solo), disponibilidade de outros nutrientes, 
manejo da adubação (forma, tipo e época de aplicação de fertilizantes), forma de amostragem do solo e idade da planta (ALVAREZ, 1996). Nesse sentido, este trabalho teve por objetivo avaliar a produção de massa seca e eficiência nutricional das espécies forrageiras Brachiaria brizantha $\mathrm{cv}$. Marandu e Massai (Panicum maximum xP. infestum) submetida a diferentes doses de fósforo buscando encontrar uma espécie com maior eficiência nutricional, visando melhorar a relação custo/benefício na reforma de pastagens em propiedades rurais destinadas a pecuária.

\section{Metodologia}

O experimento foi conduzido em casa de vegetação nas dependências do Instituto Federal de Mato Grosso (IFMT) - Campus Confresa, localizado nas coordenadas geográficas

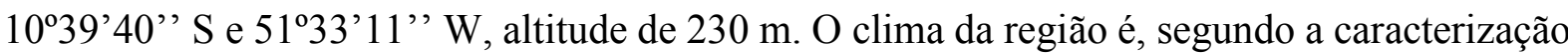
de Köeppen, do tipo Aw, tropical com estação seca de inverno (junho a agosto) e verão chuvoso (dezembro a fevereiro).

\subsection{Tratamentos e delineamento experimental}

Foram aplicadas via solução nutritiva as doses de P correspondentes 0\%, 25\%, 50\%, $75 \%$ e $100 \%$ da concentração de P em solução, recomendada por Hoagland \& Arnon (1950), que equivale a $0,0 \mathrm{mg} \mathrm{dm}^{-3} 36,9 \mathrm{mg} \mathrm{dm}^{-3}, 73,8 \mathrm{mg} \mathrm{dm}^{-3}, 110,8 \mathrm{mg} \mathrm{dm}^{-3} 147,6 \mathrm{mg} \mathrm{dm}^{-3}$ respectivamente. Sendo usado no total de aproximadamente $8 \mathrm{~L}^{-1}$ de solução nutritiva correspondendo as doses de $0,0 \mathrm{~kg} \mathrm{ha}^{-1}$ de $\mathrm{P}_{2} \mathrm{O}_{5}, 60 \mathrm{~kg} \mathrm{ha}^{-1}$ de $\mathrm{P}_{2} \mathrm{O}_{5}, 118 \mathrm{~kg}^{-1}$ de $\mathrm{P}_{2} \mathrm{O}_{5}, 177$ $\mathrm{kg} \mathrm{ha}^{-1}$ de $\mathrm{P}_{2} \mathrm{O}_{5}, 236 \mathrm{~kg} \mathrm{ha}^{-1}$ de $\mathrm{P}_{2} \mathrm{O}_{5}$.

O ensaio foi combinado em esquema fatorial $5 \times 2$, totalizando 10 tratamentos com 4 repetições para cada época de coleta. O delineamento experimental utilizado foi o de blocos casualizados, com quatro repetições.

Anteriormente à instalação do experimento, foi realizado a coleta de areia grossa a qual foi lavada com água destilada e em seguida completado os vasos plásticos de $5 \mathrm{dm}^{-3}$ e os tratamentos foram instalados semeando 10 sementes em cada vaso, das duas espécies em estudo. Sete dias após emergência foi realizado o desbaste com seleção de 5 plantas por cada unidade experimental e realizando-se a primeira aplicação da solução nutritiva. Cada vaso recebeu $20 \mathrm{ml}$ da solução nutritiva, aplicada com uso de uma seringa graduada a cada 8 dias, com a quantidade de $\mathrm{P}$ correspondente a cada tratamento, juntamente com os demais nutrientes conforme prescritos em Raij et al. (1996). Durante a condução do ensaio foi promovido irrigações a cada três dias, até a capacidade de campo. 


\subsection{Avaliações}

Nas duas épocas de avaliação (30 e 60 dias após emergência-DAE), foram realizadas coletas das gramíneas forrageiras por meio de um corte raso a $3 \mathrm{~cm}$ de altura.

Para as determinações de produção de massa seca dividiu-se a planta em parte aérea e raízes. As raízes foram lavadas com jatos de água para retirada da areia. Todo material colhido foi seco em estufa com circulação forçada de ar a $65^{\circ} \mathrm{C}$, até a obtenção de massa constante, com a determinação de massa seca em balança analítica com precisão de $0,01 \mathrm{~g}$. As plantas foram moídas separadamente (parte aérea e raiz) para a determinação da concentração de fósforo, com a obtenção do extrato utilizando digestão sulfúrica, e determinação do $\mathrm{P}$ por colorimetria pelo método molibitado de amônio, adaptado conforme proposto por (MALAVOLTA et al. 1974).

Para determinação de volume de raiz foi utilizado uma proveta graduada de $2.000 \mathrm{ml}$. Após completar com água de torneira até o volume de $1.600 \mathrm{ml}$ foi mergulhada as raízes das gramíneas na proveta e a diferença do volume inicial foi apontado como volume de raiz.

Para determinação da eficiência nutricional foi utilizado a metodologia descrita por Bataglia et al. (1983), para calcular os índices: (a) eficiência de absorção = (conteúdo total do nutriente na planta)/(matéria seca de raízes), conforme Swiader et al. (1994); (b) eficiência de transporte $=(($ conteúdo do nutriente na parte aérea $) /($ conteúdo total do nutriente na planta $)) \mathrm{x}$ 100, de acordo com Li et al. (1991); (c) eficiência de utilização = (matéria seca total produzida)2/ (conteúdo total do nutriente na planta), segundo Siddiqi \& Glass (1981).

A massa seca total foi determinada através da soma dos valores de massa seca da parte aérea e da parte radicular. Para determinar acúmulo de $\mathrm{P}$ foi utilizado produto da multiplicação da concentração de $\mathrm{P}$ e massa seca. Para determinar acúmulo de $\mathrm{P}$ total foi realizado a soma do acúmulo de $\mathrm{P}$ da parte aérea e raiz.

\subsection{Análise dos dados}

Os dados foram submetidos à análise de variância pelo teste F usando o software Sisvar. Quando constatou interação entre os fatores avaliados, procedeu com o desdobramento do fator doses de P para cada espécie forrageira. Em caso contrário, se significativo, procedeu com teste de média para cada espécie forrageira e, para doses de $\mathrm{P}$, análise de regressão, calculada para equações lineares e quadráticas. Foram consideradas apenas as equações significativas a $1(* *)$ e 5 (*) \% de probabilidade pelo teste F; quando ambas apresentaram diferença estatística, foi feita a opção por aquela com maior coeficiente de determinação $\left(\mathrm{R}^{2}\right)$. 


\section{Resultados e Discussão}

Nas Tabela 1, 2, 3 e 4 estão apresentados os resumos das análises de variância. Observou-se para a produção de massa seca parte aérea época 30 e 60 DAE e volume de raiz época $60 \mathrm{DAE}$, diferença significativa para o fator espécies, que foram influenciadas pelas doses de fósforo. Os valores estão representados em gráficos de barras (figura 1). Para massa seca total época 30 DAE observou-se diferença significativa para fator dose e, os dados ajustaram-se a equação de segundo grau linear (figura 1). Não se observando diferença significativa para massa seca de raiz nas épocas 30 e 60 DAE, massa seca total época 60 DAE e volume de raiz época $30 \mathrm{DAE}$.

Tabela 1. Quadro de análise de variância de massa seca $(\mathrm{g})$ parte aérea, raiz e total; volume de raiz $\left(\mathrm{cm}^{3}\right)$ para as épocas 30 e 60 dias após emergência - DAE. ns Não significativo a nível de 5\%. *Significativo ao nível de $5 \%$.

\begin{tabular}{ccccccccc}
\hline \multirow{2}{*}{ FV } & \multicolumn{2}{c}{ MS P.A } & \multicolumn{2}{c}{ MS Raiz } & \multicolumn{2}{c}{ MS Total } & \multicolumn{2}{c}{ Volume de Raiz } \\
\cline { 2 - 9 } & 30 DAE & 60 DAE & 30 DAE & 60 DAE & 30 DAE & 60 DAE & 30 DAE & 60 DAE \\
\hline Espécie & $16,978^{*}$ & $1102,815^{*}$ & $0,372^{\mathrm{ns}}$ & $248,701^{\mathrm{ns}}$ & $12,321^{\mathrm{ns}}$ & $2398,936^{\mathrm{ns}}$ & $87,025^{\mathrm{ns}}$ & $1458,225^{*}$ \\
Dose & $1,039^{\mathrm{ns}}$ & $168,541^{\mathrm{ns}}$ & $6,946^{\mathrm{ns}}$ & $521,950^{\mathrm{ns}}$ & $5,887^{\mathrm{ns}}$ & $1234,843^{\mathrm{ns}}$ & $75,087^{\mathrm{ns}}$ & $1207,912^{\mathrm{ns}}$ \\
Espécie x Dose & $2,313^{\mathrm{ns}}$ & $36,566^{\mathrm{ns}}$ & $8,420^{\mathrm{ns}}$ & $547,593^{\mathrm{ns}}$ & $18,971^{*}$ & $807,486^{\mathrm{ns}}$ & $54,087^{\mathrm{ns}}$ & $2299,787^{\mathrm{ns}}$ \\
\hline C.V $(\boldsymbol{\%})$ & 82,910 & 92,920 & 70,510 & 80,140 & 51,400 & 65,740 & 62,530 & 66,920 \\
Média & 1,124 & 14,327 & 3,027 & 26,897 & 4,151 & 41,223 & 8,775 & 71,925 \\
\hline
\end{tabular}

Observou-se que a espécie Brachiaria obteve maior produção de massa seca parte aérea quando comparada ao Massai nas duas épocas testada (figura 1). A espécie Brachiaria conseguiu desenvolver-se melhor em parte aérea e radicular, resultados também encontrado por Silva (1996), que verificou incrementos na produção de massa seca da parte aérea e das raízes, bem como na concentração de fósforo nas folhas de capim Brachiaria devido ao aumento do suprimento de fósforo na solução nutritiva, confirmando os resultados obtidos nesta pesquisa, onde foi observado maior incremento na produção de parte aérea do que radicular. Rossi e Monteiro (1999), também observou acréscimos mais acentuados na produção de parte aérea que nas raízes, em estudos com gramíneas da espécie Brachiaria, fato também constatado por Martinez (1980), em pesquisa com a espécie Braquiária.

Segundo Ferri (1985), a produção de parte aérea e área foliar é essencial devido ser as folhas as principais responsáveis pela captação da energia solar e pela produção de matéria orgânica através da fotossíntese.

Para volume de raízes época 60 DAE verificou-se diferença significativa entre as espécies, sendo a Brachiaria a espécie que obteve maior resposta em função das doses de $\mathrm{P}$ empregadas, obtendo maior volume de raízes (figura 1). Raij (1991) explica que o P em quantidades adequadas, estimula o desenvolvimento radicular e promove a precocidade da 
produção. Gardner et al. (1985), citado por Rossi e Monteiro (1999), afirmam que plantas bem supridas com $\mathrm{P}$ desenvolvem mais raízes que plantas deficientes. $\mathrm{O}$ mesmo autor ainda afirma que isso ocorre devido a disponibilidade do fósforo influenciar a fotossíntese, que por sua vez resulta em aumento no crescimento radicular.

Para massa seca total época 30 DAE, verificou-se interação entre os fatores (doses x espécie). No desdobramento da interação para o estudo de doses de $\mathrm{P}$ dentro de cada espécie de gramínea, observou-se efeitos significativos para espécie Massai, que promoveu efeito linear positivo (figura 1). Na época 30 DAE a espécie Massai obteve resposta crescente em função das doses de $\mathrm{P}$, tendo teto máximo de produção na dose $100 \%$. Tais resultados estão de acordo com os observados por Oliveira et al. (2004), que constatou incremento na produção de massa seca do capim-de-raiz (Chloris orthonoton) em função das doses de P aplicadas. Através desta pesquisa ficou evidente a velocidade de desenvolvimento (parte aérea e raiz) da espécie Massai na fase inicial de implantação (30 DAE). Observou-se que é uma espécie pouco responsiva adubação fosfatada o que explica o seu rápido desenvolvimento a curto prazo, sendo, este desenvolvimento cessado aos 60 DAE, onde verificou maior crescimento para a espécie Brachiaria. Essa característica da espécie Massai pode estar associado a sua habilidade de adaptar-se bem a condições limitantes e ambientes adversos.

Figura 1. (A) Massa seca parte aérea época 30 DAE. (B) Massa seca parte aérea época 60 DAE. (C) Massa seca total época 30 DAE. (D) Volume de raiz época 60 DAE.

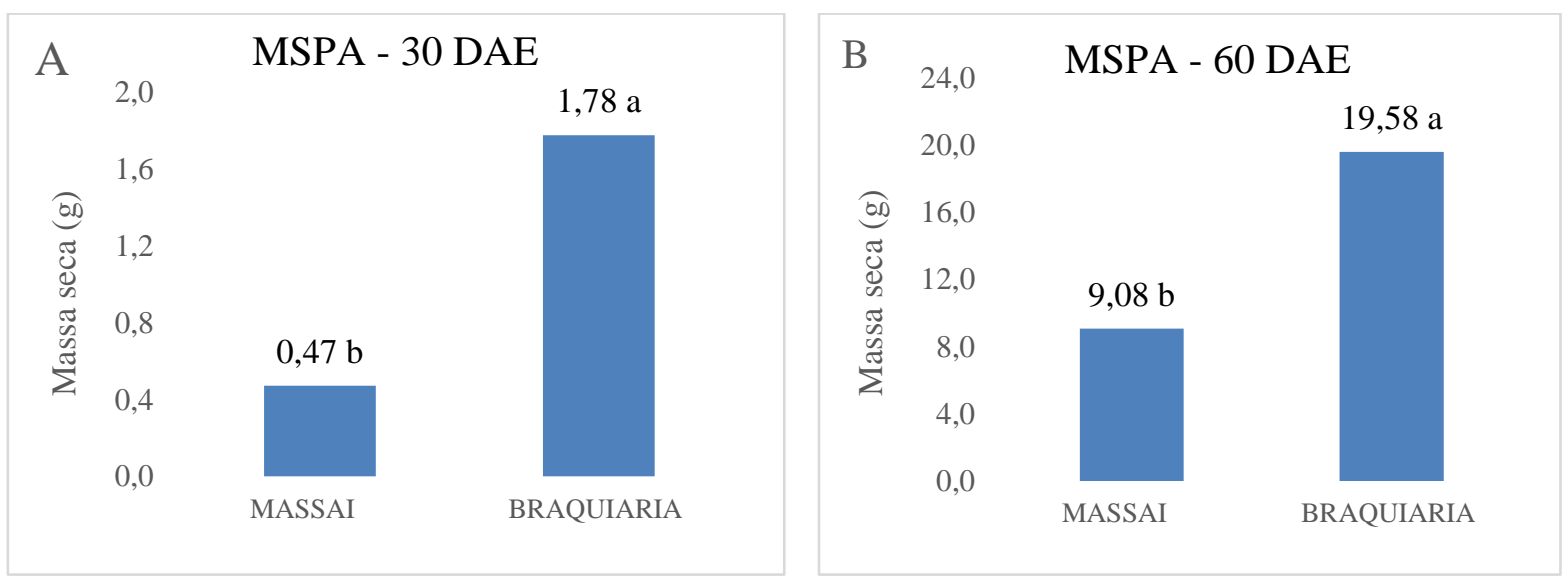



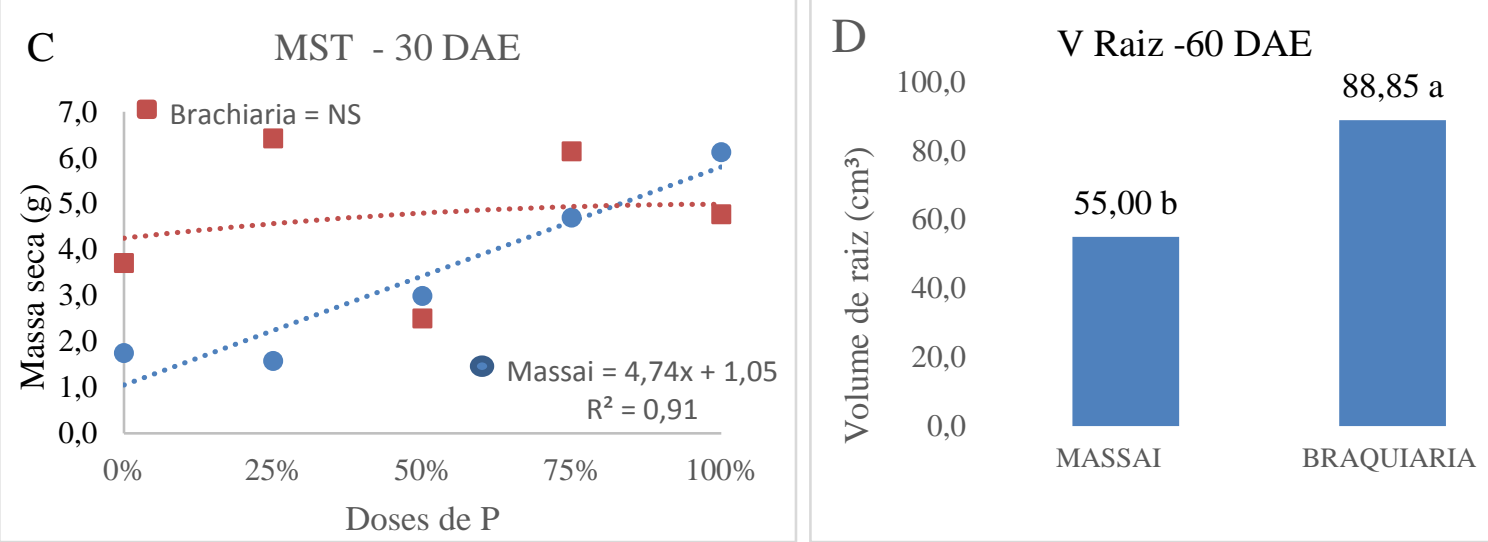

Neste estudo observou-se que a espécie Brachiaria obtém-se maior eficiência de extrair e acumular nutriente. Essa habilidade da espécie promove um melhor desenvolvimento e maior incremento na produção vegetal (parte aérea e raiz) a longo prazo, o que evidencia maior produção de massa seca total para a gramínea que pode ser constatado nos resultados obtidos na época 60 DAE quando comparado a espécie Massai na mesma época de avaliação. Tal ocorrência pode ser associado ao fato da genética da planta e também da eficiência nutricional da espécie, o que condiciona uma maior realização de fotossíntese e produção de energia, por sua vez, potencializa o máximo desenvolvimento da planta (parte aérea e raiz) (tabela 1).

Segundo Malavolta (2006), o P promove maior crescimento da forrageira principalmente por desempenhar função estrutural na planta além de fazer parte de compostos orgânicos como o ATP, os aminoácidos e de todas as enzimas e assim participa de diversos processos metabólicos, em especial no processo de transferência e de armazenamento de energia.

Segundo Melo (2016), teor refere-se à concentração, (por exemplo, \%, g/kg, mg/kg), enquanto que o conteúdo se refere à quantidade do elemento em um órgão, parte aérea, raízes, toda a planta (por exemplo, g/planta, mg/planta).

Para concentração de P no tecido vegetal não constatou diferença significativa na parte aérea e radicular na época 30 DAE. Observou-se diferença significativa para fator espécie parte radicular época $60 \mathrm{DAE}$ (tabela 2). Os dados estão representados em gráficos de barras (figura 2). Verificou-se interação dos fatores (doses e espécie) para parte aérea época 60 DAE (tabela 2). No desdobramento da interação para o estudo de doses de $\mathrm{P}$ dentro de cada espécie de gramínea observou-se diferença significativa para espécie Brachiaria. Os dados melhor se ajustaram na equação polinomial de segundo grau (figura 2), com $\mathrm{R}^{2}$ de 0,91 . 
Tabela 2. Quadro de análise de variância da concentração de fósforo (P) $\mathrm{g} \mathrm{kg}^{-1}$ parte aérea e raiz épocas 30 e 60 dias após emergência - DAE. ${ }^{\text {ns }}$ Não significativo ao nível de 5\%. *Significativo ao nível de $5 \%$

\begin{tabular}{ccccccc}
\hline \multirow{2}{*}{ FV } & \multicolumn{2}{c}{ C P P.A } & & \multicolumn{2}{c}{ C P. Raiz } \\
\cline { 2 - 3 } \cline { 5 - 6 } & 30 DAE & 60 DAE & & 30 DAE & 60 DAE \\
\hline Espécie & $0,087^{\mathrm{ns}}$ & $0,000336^{\mathrm{ns}}$ & & $0,019^{\mathrm{ns}}$ & $0,554^{*}$ \\
Dose & $0,029^{\mathrm{ns}}$ & $0,125^{\mathrm{ns}}$ & & $0,146^{\mathrm{ns}}$ & $0,041^{\mathrm{ns}}$ \\
Espécie x Dose & $0,132^{\mathrm{ns}}$ & $0,210^{*}$ & & $0,090^{\mathrm{ns}}$ & $0,041^{\mathrm{ns}}$ \\
\hline C.V $(\boldsymbol{\%})$ & 44,910 & 67,600 & & 108,450 & 95,730 \\
Média & 0,512 & 0,404 & & 0,296 & 0,185 \\
\hline
\end{tabular}

Observou-se tendência ao declínio da curva em função das doses crescente de P. Provavelmente isso ocorreu devido a espécie Brachiaria, época 30 DAE, estar em fase de implantação (crescimento vegetativo). Já na época 60 DAE a espécie conseguiu maior desenvolvimento (parte aérea e radicular), consequentemente maior incremento na produção de matéria seca, evidenciando que a tendência ao declínio da curva em função das doses crescentes de $\mathrm{P}$ foi promovida pelo efeito diluição do elemento $\mathrm{P}$ na planta, que também foi observado por Prezotott et al. 2012 e proposto por Lemaire et al. 1997.

Para concentração de P radicular, notou-se maior concentração para espécie Brachiaria. Segundo Crusciol et al. (2005) e Ribeiro et al. (2010), a adubação fosfatada atua também no desenvolvimento radicular das culturas e favorece a absorção de água e nutrientes que está de acordo com resultados encontrados nesta pesquisa. Segundo Almeida (2016), algumas plantas tem como vantagem, respostas às baixas concentrações de $\mathrm{P}$ no solo pelo aumento do sistema radicular, desenvolvendo rapidamente raízes laterais com abundantes pêlos radiculares que melhoram a habilidade da planta em explorar o solo em busca de novas reservas de $\mathrm{P}$ do solo, e o extraem eficientemente quando áreas com alto teor de P são encontradas

Figura 2. (A) Concentração de P parte aérea época 60 DAE. (B) Concentração de P raiz época 60 DAE.

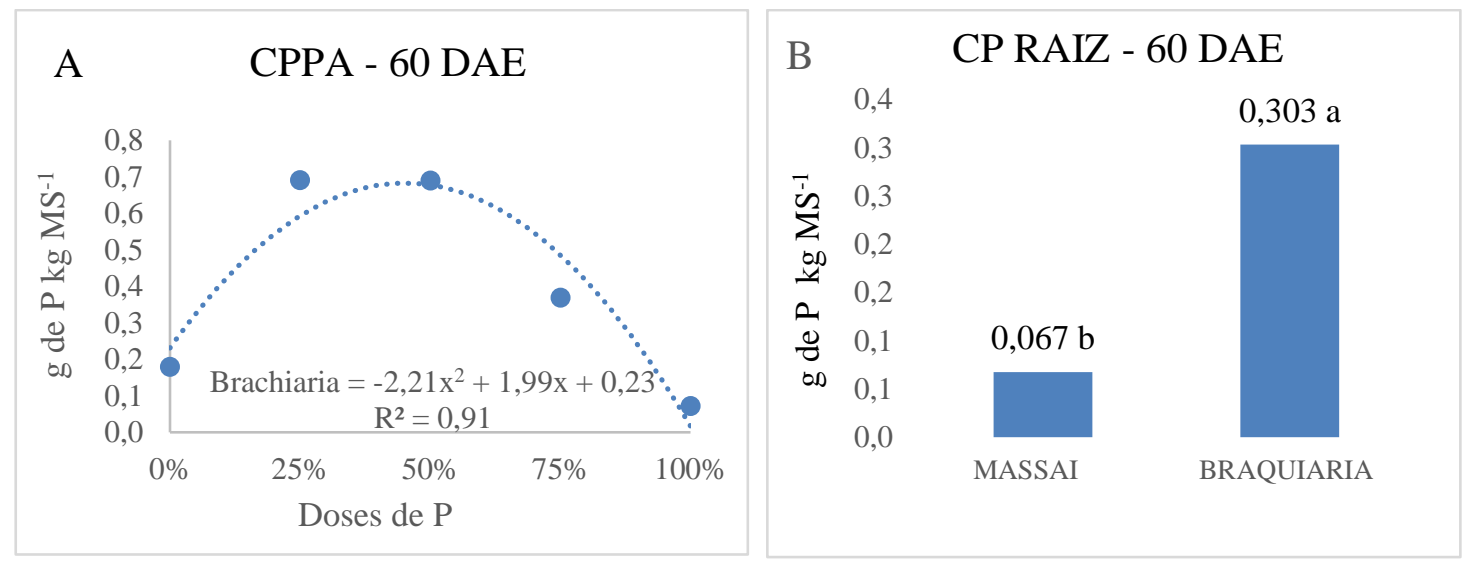

Segundo Faquin (2005), citado por Melo (2016), a literatura reporta que o fósforo é um dos macronutrientes menos exigido pelas plantas e, que para o ótimo crescimento vegetal, a 
quantidade deste nutriente varia, dependendo da espécie e do órgão analisado, de 0,1 a 0,5\% na matéria seca. Melo (2005) explica que há uma série de trabalhos científicos com enfoque na adubação fosfatada em gramíneas e também as respostas da espécie em crescimento e produção, a determinação do nível crítico e da concentração de $\mathrm{P}$ no tecido vegetal. Outros trabalhos avaliando concentração de $\mathrm{P}$ em gramíneas, observou variação de 0,7 a 6,8 g. $\mathrm{kg}^{-1}$ de P na planta recebendo doses crescentes de P (MARTINEZ, 1980; ROSSI \& MONTEIRO, 1999).

Para concentração de P parte aérea época 60 DAE observou-se que a espécie Brachiaria obteve concentração máxima de $0,69 \mathrm{~g} \mathrm{~kg}^{-1}$ de P. Para parte radicular época 60 DAE verificouse concentração máxima de $0,303 \mathrm{~g} \mathrm{~kg}^{-1}$ de $\mathrm{P}$ (figura 2). Costa et al. (2007), observaram concentrações de até 1,8 $\mathrm{g} \mathrm{kg}^{-1}$ em Brachiaria brizanta em regime de corte. Em observações feitas por Guss et al. (1990), verificaram-se que os níveis críticos de P na parte aérea de plantas de $B$. brizanta cultivadas em latossolos variaram de 1,3 a $2,5 \mathrm{~g} \mathrm{~kg}^{-1}$; resultados semelhantes também encontrado por Santos-Filho et al. (2007), em estudos dos níveis adequados de P para gramíneas, que conclui-se ficar em torno de 1,0 a $2,3 \mathrm{~g} \mathrm{~kg}^{-1}$.

Para Melo (2016), a faixa de concentração adequado de P na parte aérea de capins é de 0,8 a $3 \mathrm{~g} \mathrm{~kg}^{-1}$. Em contraposição a esse trabalho, verificou-se concentrações de $\mathrm{P}$ abaixo do citado para parte aérea. Já Rossi e Monteiro (1999), obtiveram resultados semelhantes para concentrações de fósforo em experimento com capim-braquiária variando de $0,43 \mathrm{~g} \mathrm{~kg}^{-1} \mathrm{na}$ menor dose aplicada, até um máximo de $3,6 \mathrm{~g} \mathrm{~kg}^{-1}$ na mais alta dose de fósforo. Nesta pesquisa observou-se que a concentração de $\mathrm{P}$ nas raízes foram inferior ao da parte aérea para a espécie Brachiaria (figura 2), fato também constatado por Martinez (1980) e Almeida (1998), em estudos com capim Brachiaria onde verificou baixas concentrações desse nutriente nas raízes em relação à parte aérea da gramínea, corroborando com os resultados de Silva (1996) e Almeida (1998).

Segundo Guss et al. (1990), citado por Rossi e Monteiro (1999), o aumento na concentração de fósforo na matéria seca com o aumento na dose de fósforo mostra que espécies do gênero Brachiaria possuem capacidade de acumularem fósforo no tecido após atingir o crescimento máximo, Martinez (1980) e Almeida (1998), também observaram que o aumento das doses de fósforo na solução nutritiva proporcionou incremento na concentração de fósforo do capim Braquiária podendo também se constituir em um mecanismo de defesa da planta, que acumula fósforo inorgânico nos vacúolo celulares como reserva para mobilizá-lo em condições adversas.

Para acúmulo de P, observou-se diferença significativa na parte aérea, época 30 e 60 DAE e parte radicular, época 60 DAE para o fator espécies (Brachiaria e Massai). Os dados 
estão representados em gráficos de barras (figura 3). Para acúmulo de $\mathrm{P}$ parte radicular época 30 DAE observou-se diferença significativa para fator dose. Os dados se ajustaram na equação quadrática polinomial de segundo grau.

Tabela 3. Quadro de análise de variância de acúmulo de fosforo $(\mathrm{P})$ em mg g, parte aérea, raiz e total nas épocas 30 e 60 dias após emergência - DAE. ${ }^{\text {ns }}$ Não significativo ao nível de $5 \%$. *Significativo ao nível de 5\%

\begin{tabular}{|c|c|c|c|c|c|c|}
\hline & \multicolumn{2}{|c|}{ A P P.A } & \multicolumn{2}{|c|}{ A P Raiz } & \multicolumn{2}{|c|}{ A P Total } \\
\hline & $30 \mathrm{DAE}$ & $60 \mathrm{DAE}$ & $30 \mathrm{DAE}$ & $60 \mathrm{DAE}$ & $30 \mathrm{DAE}$ & $60 \mathrm{DAE}$ \\
\hline Espécie & $6,159 *$ & $279,666^{*}$ & $0,206^{\mathrm{ns}}$ & $173,172 *$ & $4,109^{\mathrm{ns}}$ & $893,006^{\mathrm{ns}}$ \\
\hline Dose & $0,572^{\mathrm{ns}}$ & $90,290^{\mathrm{ns}}$ & $2,750 *$ & $3,784^{\mathrm{ns}}$ & $2,536^{\mathrm{ns}}$ & $112,143^{\mathrm{ns}}$ \\
\hline Espécie x Dose & $1,102^{\mathrm{ns}}$ & $124,929^{\mathrm{ns}}$ & $0,955^{\mathrm{ns}}$ & $18,160^{\mathrm{ns}}$ & $3,865^{*}$ & $225,125^{*}$ \\
\hline C.V (\%) & 107,100 & 129,470 & 87,950 & 91,190 & 64,460 & 86,680 \\
\hline Média & 0,610 & 5,978 & 0,897 & 3,793 & 1,507 & 9,771 \\
\hline
\end{tabular}

Para acúmulo de $\mathrm{P}$ total observou-se diferença significativa na interação dos fatores (doses e espécie) nas épocas 30 e 60 DAE. Os valores ajustaram a equação polinomial de segundo grau (figura 3).

Para parte aérea verificou-se nas duas épocas de avaliações incremento no acúmulo de P para espécie Brachiaria, sendo esta, bem superior a quantidade observada para a espécie Massai. Melo (2005), também observou diferença significativa no total do elemento P extraído pela parte aérea do capim Brachiaria para as doses de $\mathrm{P}$ em diferentes períodos de avaliações. Nunes et al. (2008), encontrou resultados semelhantes, observando maiores concentrações e acúmulo de $\mathrm{P}$ em Brachiaria do que em Panicum, na menor dose desse elemento, sugerindo maior eficiência de aquisição de $\mathrm{P}$, quando esse nutriente encontra-se em baixa disponibilidade no solo.

Figura 3. (A) acúmulo de $P$ parte aérea época 30 DAE. (B) acúmulo de $P$ parte aérea época 60 DAE. (C) acúmulo de $\mathrm{P}$ raiz época 30 DAE. (D) acúmulo de $\mathrm{P}$ raiz época 60 DAE. (E) acúmulo de $\mathrm{P}$ total época 30 DAE. (F) acúmulo de $\mathrm{P}$ total época 60 DAE.

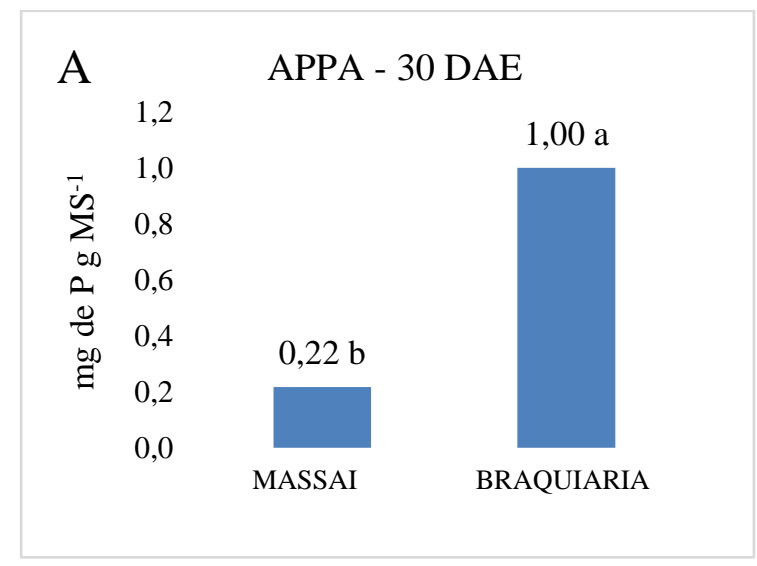

\begin{tabular}{|c|c|c|c|}
\hline \multirow[t]{2}{*}{ B } & \multicolumn{3}{|c|}{ APPA - 60 DAE } \\
\hline & 10,0 & & $8,62 \mathrm{a}$ \\
\hline \multirow{6}{*}{$\begin{array}{l}\sum_{\infty}^{1} \\
\sum_{0}^{n} \\
0 \\
0 \\
0 \\
0\end{array}$} & 8,0 & & \\
\hline & 6,0 & & \\
\hline & 4,0 & $3,33 \mathrm{~b}$ & \\
\hline & 2,0 & & \\
\hline & 0,0 & & \\
\hline & & MASSAI & BRAQUIARIA \\
\hline
\end{tabular}



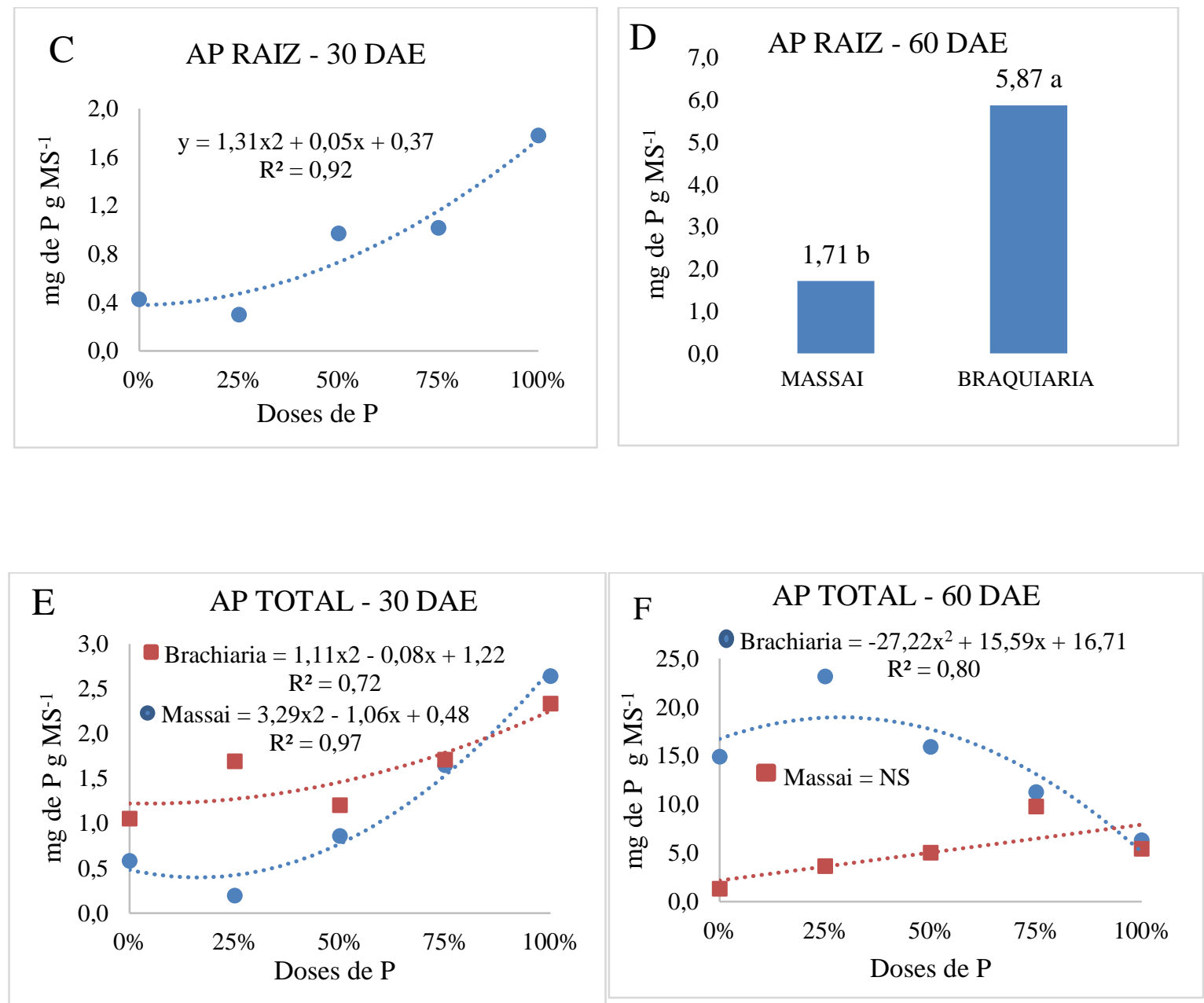

Santos (1999), trabalhando com espécie Brachiaria observou que o acúmulo de P na parte aérea da forrageira acompanhou a variação da produção de massa seca da gramínea, confirmando os resultados encontrados nesta pesquisa, onde as respostas para acúmulo de $\mathrm{P}$ parte aérea acompanhou a variação de resposta de massa seca da espécie nas duas épocas de avaliação (Figura1).

Para acúmulo de $\mathrm{P}$ parte radicular época 30 DAE, observou-se diferença significativa para fator dose. Os dados ajustaram-se na equação polinomial de segundo grau (figura 3). Verificou-se uma tendência crescente positiva de resposta no aumento das doses de $\mathrm{P}$, concordando com Silva (1996), que também verificou aumento na quantidade acumulada de fósforo nas raízes e parte aérea de capim Braquiária, conforme o aumento das doses de fósforo na solução.

Para acúmulo de $\mathrm{P}$ radicular época $60 \mathrm{DAE}$, verificou-se maior acúmulo para espécie Brachiaria (figura 3). Observou-se também maior incremento na concentração de P e volume de raiz para a espécie, na mesma época de avaliação (figura 1 e 2). Amaral et al. (2012), observou que o acúmulo de um nutriente é dependente da concentração deste no tecido e, 
principalmente, da produção de massa seca, o que evidencia os resultados encontrados por este trabalho. Por outro lado, a ocorrência desse evento pode estar associado a genética da gramínea, morfologia e eficiência nutricional (absorção e transporte de nutrientes) que influencia todos os processos fisiológico e morfológicos, impulsionando o desenvolvimento de folhas e parte aérea da planta para a realização de fotossínteses e consequentemente em maior produção de raízes para absorção de nutrientes.

Para acúmulo de $\mathrm{P}$ total época $30 \mathrm{DAE}$ verificou-se diferença significativa para as duas espécie (Brachiaria e Massai) (figura 3). Para a espécie Brachiaria constatou tendência crescente positiva com $\mathrm{R}^{2}$ de 0,72 . A espécie Massai também obteve comportamento parecido com tendência crescente positiva com $\mathrm{R}^{2}$ de 0,92 . Constatou-se que na época $30 \mathrm{DAE}$ houve incremento no acúmulo de $\mathrm{P}$ para duas espécie de acordo que aumentou as doses de $\mathrm{P}$, verificando maior incremento para a espécie Massai. Melo (2005) explica que o total de nutriente acumulado pela planta é em razão da concentração desse nutriente no tecido da planta e da produção de massa seca da mesma, que confirma os resultados encontrados por essa pesquisa, onde verificou-se aumento linear positivo na produção de massa seca total, época 30 DAE, para a espécie Massai (figura 1).

Para acúmulo de $\mathrm{P}$ total época 60 DAE observou-se diferença significativa para a espécie Brachiaria com tendência decrescente de acúmulo de $\mathrm{P}$ em relação as doses aplicadas, com $\mathrm{R}^{2}$ de 0,80 (figura 3). Embora não tenha observado diferença significativa para produção de massa seca total para espécie na época $60 \mathrm{DAE}$, verificou-se diferença significativa para concentração do elemento P para mesma época e espécie (figura 2). Confirmando a constatação de Melo 2005 e Amaral et al. 2012.

Para eficiência de absorção e transporte observou-se diferença significativa para fator espécie nas épocas 30 e 60 DAE, não constatando diferença significativa para eficiência de utilização (tabela 4). Os dados estão representados em gráficos de barras (figura 4).

Tabela 4. Quadro de análise de variância de eficiência de absorção (mg nutriente/M.S raízes), transporte (\%) e utilização $\left((\mathrm{M} . \mathrm{S})^{2} / \mathrm{g}\right.$ nutriente acumulado) nas épocas 30 e 60 dias após emergência - DAE ns Não significativo ao nível de $5 \%$. *Significativo ao nível de $5 \%$

\begin{tabular}{cccccccc}
\hline \multirow{2}{*}{ FV } & \multicolumn{2}{c}{ E.A } & & \multicolumn{2}{c}{ E.T } & \multicolumn{2}{c}{ E.U } \\
\cline { 2 - 3 } \cline { 7 - 8 } & 30 DAE & 60 DAE & & 30 DAE & 60 DAE & 30 DAE & 60 DAE \\
\hline Espécie & $3,037^{*}$ & $1,080^{*}$ & & $7839,412^{*}$ & $15021,554^{*}$ & $12,215^{\mathrm{ns}}$ & $48679,645^{\mathrm{ns}}$ \\
Dose & $0,167^{\mathrm{ns}}$ & $0,151^{\mathrm{ns}}$ & & $930,737^{\mathrm{ns}}$ & $1894,229^{\mathrm{ns}}$ & $23,692^{\mathrm{ns}}$ & $267438,824^{\mathrm{ns}}$ \\
Espécie x Dose & $0,326^{\mathrm{ns}}$ & $0,150^{\mathrm{ns}}$ & & $505,988^{\mathrm{ns}}$ & $841,098^{\mathrm{ns}}$ & $150,770^{\mathrm{ns}}$ & $195279,153^{\mathrm{ns}}$ \\
\hline C.V (\%) & 108,260 & 94,450 & & 65,820 & 59,850 & 73,890 & 108,050 \\
Média & 0,660 & 0,459 & & 41,975 & 63,248 & 13,798 & 337,185 \\
\hline
\end{tabular}


Segundo Rozane et al. (2007), a produção das culturas é afetada diretamente pela eficiência nutricional. $\mathrm{O}$ autor explica que o termo eficiência nutricional está relacionado a eficiência de absorção, transporte e utilização, sendo a eficiência de absorção que indica a capacidade da planta em extrair nutrientes do meio de cultivo (solução nutritiva). O autor salienta que os mecanismos desenvolvidos pelas plantas para alta eficiência de absorção diferem entre espécies. Nesta pesquisa, observou-se que a espécie Brachiaria obteve maior eficiência de absorção (figura 4), refletindo em uma maior produção de massa seca (parte aérea e radicular) (figura 1), o que evidenciou uma relação entre eficiência de absorção e produção de massa seca, concordando com Fayad (1998), que afirma existir uma estreita relação positiva e significativa entre as taxas de crescimento e de absorção de nutrientes.

Segundo Almeida (2016), a absorção de P pelas plantas é proporcional à densidade das raízes, igualmente, o incremento da área superficial da massa radicular, maximiza a habilidade da planta em buscar e absorver o P do solo. Rozane et al. (2007), salienta que as eficiências nutricionais variam em função das modificações genéticas de cada planta, sendo uma interessante ferramenta para explicar a produção de matéria seca e, consequentemente aumento de produção. Estas constatações são confirmadas por esta pesquisa (figura 1 e 4).

Quanto a eficiência nutricional, segundo Marschner (1995), citado por Rozane et al. (2007), as diferenças genotípicas quanto à eficiência nutricional ocorrem por várias razões, as quais estão relacionadas à absorção, transporte e utilização dos nutrientes pelas plantas. O autor afirma que essas diferenças genotípicas envolvidas na nutrição mineral podem ser explicadas, de acordo com Gerloff \& Gabelman (1983), por aspectos morfológicos e fisiológicos relacionados à absorção de nutrientes.

Figura 4. (A) Eficiência de absorção época 30 DAE. (B) Eficiência de absorção época 60 DAE. (C) Eficiência de transporte época 30 DAE. (D) Eficiência de transporte época 60 DAE.
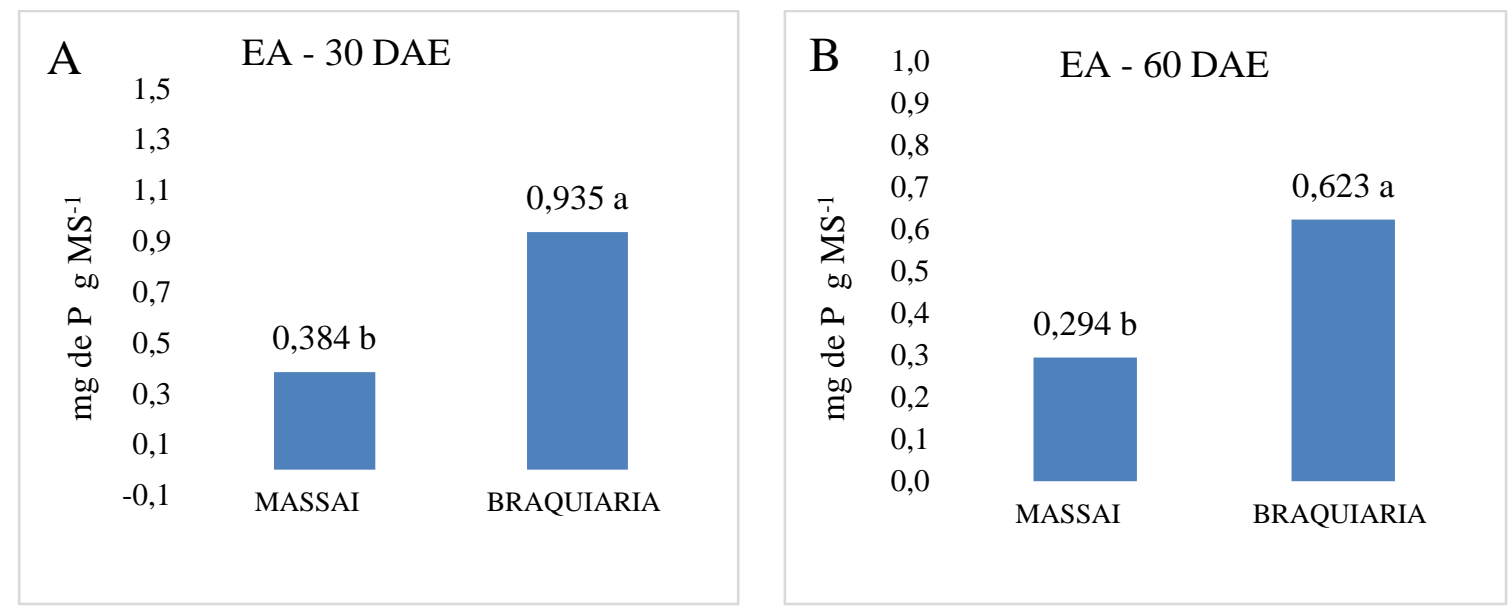

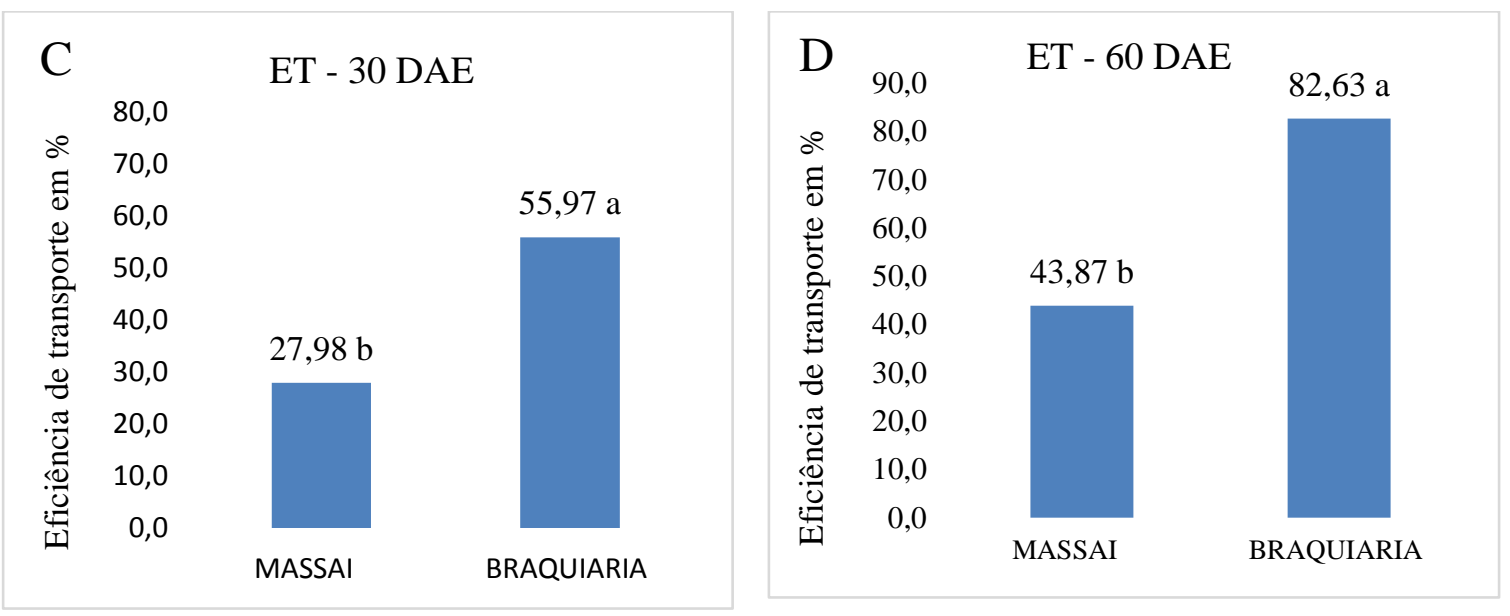

Para eficiência de transporte, verificou-se que a espécie Brachiaria obteve melhor eficiência comparado a espécie Massai. Rozane et al. (2007), considera que a eficiência de transporte é a capacidade da planta em transportar os nutrientes das raízes para a parte aérea da planta. Isso revela que a espécie Brachiaria obteve maior eficiência em bombear ( transportar) o elemento $\mathrm{P}$ absorvido pelo sistema radicular para parte aérea da gramínea, consequentemente fazendo com que a forrageira desenvolvesse mais parte aérea, proporcionando assim, maior produção de fotossíntese e gerando mais foto assimilados e assim fornecendo mais energia para planta se desenvolver tanto em parte aérea quanto em sistema radicular, tornando um ciclo, e com isso, maior incremento na produção de matéria seca.

Neste trabalho observou-se valores de coeficiente de variação $(\mathrm{CV})$ um tanto quanto elevados, o que não é considerado como inadequado. Melo (2016) explica que ainda que o coeficiente de variação (CV) de alguns parâmetros esteja elevado, não pode ser considerado como inadequado, pois, segundo Blum (1988), citado por Melo (2016), estudo englobando estresse mineral podem apresentar valores mais elevados de coeficiente de variação.

Nesta pesquisa verificou-se que as duas espécie de gramíneas forrageiras estudadas (Brachiaria e Massai) obtiveram comportamentos de respostas diferentes quanto a produtividade, concentração e acúmulo de $\mathrm{P}$ e eficiência nutricional, mesmo estando em mesmas condições de tratamentos, manejo, clima e doses de P. Uma possível explicação para esses comportamentos pode ser atribuída a genética, morfologia, fisiologia, estrutura vegetal e mecanismo de defesa de cada espécie, que está relacionado a estratégia de sobrevivência e adaptação de cada gramínea estudada, constatando melhores resultados para espécie Brachiaria. Andrade (2003), em estudo com Brachiaria brizantha cv. Marandu verificou-se que a espécie tem sido muito utilizada devido as suas características, como adaptação em solos de baixa 
fertilidade e resistência à cigarrinha das pastagens, elevada produtividade quando devidamente adubada e manejada.

Segundo Rozane et al. (2007), o cultivo de plantas em vasos, utilizando-se de solução nutritiva, é uma ferramenta muito útil nos estudos de nutrição mineral e na busca de soluções e genótipos mais eficientes. Os resultados desse experimento confirmam a importância da adubação fosfatada para plantas forrageiras. Que embora o P seja um elemento pouco requerido pelas plantas (FAQUIN, 2005) mais é de fundamental importância para instalação, crescimento e produtividade das gramíneas, por se tratar de um nutriente limitante. Sendo a baixa eficiência das adubações fosfatadas um grande problema e que evidencia a necessidade de estudos para obtenção de melhores dose de $\mathrm{P}$, buscando aumentar a produção e reduzir custos.

\section{Considerações Finais}

Tendo em vista os resultados obtidos neste trabalho em condições controladas, concluise, que a espécie Brachiaria brizantha cv. Marandu é mais eficiente na absorção e transporte do nutriente $\mathrm{P}$ do que a espécie Massai (Panicum maximum x P.infestum), independente da dose utilizada, que consequentemente resulta em maior produção de massa seca e raiz, sem, contudo, ser mais eficiente na utilização do fósforo, evidenciando ser mais responsiva a adubação fosfatada.

\section{Referências}

ALMEIDA, J. C. R. Combinações de doses de fosforo e magnésio na produção e nutrição de duas espécies de brachiaria. 1998. 81 f. Dissertação (Mestrado em Agronomia) - Escola Superior de Agricultura Luiz de Queiroz - Universidade de São Paulo, Piracicaba, 1998.

ALVAREZ V., V.H. Correlação e calibração de métodos de análise de solos. In: ALVAREZ V., V.H.; FONTES, L.E.F. \& FONTES, M.P.F., eds. O solo nos grandes domínios morfoclimáticos do Brasil e o desenvolvimento sustentado; Viçosa, MG: Sociedade Brasileira de Ciência do Solo, 1996. p.615-645.

AMARAL, C. S.; SILVA, E. B.; AMARAL, W. G.; NARDIS, B. O. Crescimento de Brachiaria brizantha pela adubação mineral e orgânica em rejeito estéril da mineração de quartzito. Bioscience Journal, v. 28, Supplement 1, p. 130-141, 2012.

BATAGLIA, O. C.; FURLANI, A. M. C.; TEIXEIRA, J. P. F.; FURLANI, P. R.; GALLO, J. R. Métodos de análise química de plantas. Campinas: IAC, 1983. 48 p. (IAC. Boletim Técnico, 78).

BLUM, A. Plant Breeding for Stress Environments. Boca Raton: CRC Press, 1988. 
COSTA, K.A.P.; OLIVEIRA, I.P.; FAQUIM, V.; NEVES, B.P.; RODRIGUES, C.; SAMPAIO, F.M.T. Intervalo de corte na produção de massa seca e composição químicobromatológica da Brachiaria brizantha cv. MG-5. Ciência e Agrotecnologia, v.31, n.8, , 2007, p.1197-1202.

CRUSCIOL, C.A.C.; MAUAD, M.; ALVAREZ, R. de C.F.; LIMA, E. do V.; TIRITAN, C.S. Doses de fósforo e crescimento radicular de cultivares de arroz de terras altas. Bragantia, Campinas, v.64, n.4, p. 643-649, 2005.

FAQUIN, V. Nutrição Mineral de Plantas. 2005. 186 f. Dissertação Pós-Graduação Lato Sensu (Especialização a distância Solos e Meio Ambiente) - Universidade Federal de Lavras FAEPE, Lavras/MG, 2005.

FAYAD, J. A. Absorção de nutrientes, crescimento e produção do tomateiro cultivado em condições de campo e de estufa. 1998. 81 f. Tese (Mestrado) - Universidade Federal de Viçosa, Viçosa/MG.

FERRI, M. G. (Coord.). Fisiologia vegetal. 2.ed.rev.atual. Sao Paulo: EPU, 1985.

FILHO, F.L.R. Crescimento, teores e acúmulo de nutrientes em plantas de milho fertirrigadas com água residuária do beneficiamento de frutos de café. $2013.76 \mathrm{f}$. Dissertação (Mestrado) - Universidade Federal do Espirito Santo, Vitoria, 2013.

GARDNER, F. P.; PEARCE, R. B.; MITCHELL, R. L. Physiology of crop plants. Ames: The Iowa State University, 1985.

GERLOFF, G.C. \& GABELMAN, W.H. Genetic basis of inorganic plant nutrition. In: Laüchli, A.; Bieleski, R.L. (Eds.). Inorganic plant nutrition. Encyclopedia of Plant Physiology. Berlim, New York, Tokyo: Springer-Verlag, 1983, p.453-486.

GNIAZDOWSKA, A.; KRAWCZAK, A.; MIKULSKA, M. \& RYCHTER, A.M. Low phosphorus nutrition alters beans plants' ability to assimilate and translocate nitrate. J. Plant Nut. 22, p. 51-563, 1999.

HOAGLAND, D.R.; ARNON, D. I. The water culture method for growing plants without soils. Berkeley: California Agricultural Experimental Station, 1950.

HOLFORD, I.C.R. Soil phosphorus: its measurement, and its uptake by plants. Australian. Journal of Soil Research, 35, p. 227-239, 1997.

LEMAIRE, Ed. G. Diagnostico do status de nitrogênio nas lavouras. Berlim: Springer, 1997.

LI, B.; McKEAND, S.E.; ALLEN, H.L. Genetic variation in nitrogen use efficiency of loblolly pine seedlings. Oxford Academic Forest Science, v.37, n.2, p.613-626, 1991. Disponível em: https://doi.org/10.1093/forestscience/37.2.613. Acessado em: 02 de março de 2019.

MACEDO, M.C.M. Pastagens no ecossistema cerrado: pesquisa para o desenvolvimento sustentável. In: SIMPÓSIO SOBRE PASTAGENS NOS ECOSSISTEMAS BRASILEIROS: 
PESQUISAS PARA O DESENVOLVIMENTO SUSTENTÁVEL, Brasília. Anais... Brasília: SBZ, 1995. p. 28-62.

MALAVOLTA, E. Manual de nutrição mineral de plantas. São Paulo: Agronômica Ceres, 2006.

MALAVOLTA, E. Nutrição mineral e adubação de plantas cultivadas. São Paulo-SP: Pioneira, 1974.

MARSCHNER, H. Mineral nutrition of higher plants. London, Academic Press, 1995.

MARTINEZ, H. E. P. Níveis críticos de fósforo em Panicum maximum (Stapf) Prain, Brachiaria humidicola (Rendle) Schweickerdt, Digitaria decumbens Stent, Hyparrhenia rufa (Ness) Stapf, Melinis minutiflora Pal de Beauv, Panicum maximum Jacq. e Penisetum purpureum Schum. 1980. 90 f. Dissertação (Mestrado) - Escola Superior de Agricultura Luiz de Queiroz, Piracicaba/SP, 1980.

MELO, M. P de. Efeito de fontes e doses de fósforo em gramíneas forrageiras. 2016. 112 f. Tese (Doutorado em Produção Vegetal) - Universidade Federal do Tocantins, Gurupi/TO, 2016.

MELO, S. P. de. Silício e fósforo para estabelecimento do capim-marandu num latossolo Vermelho-Amarelo. 2005. 110 f. Tese (Doutorado) - Escola Superior de Agricultura Luiz de Queiroz - Universidade de São Paulo, Piracicaba, 2005.

OLIVEIRA, T. N. Influência do fósforo e de diferentes regimes de corte na produtividade e no perfilhamento do capim-de-raiz (Chloris orthonoton Doell). Revista Brasileira de Zootecnia, 33, p.60-67, 2004.

PREZOTTI, L. C.; MORELI, A. P.; SOARES, S. F.; ROCHA, A. C. da. Teores de nutrientes nas aguas residuais do café e características químicas do solo após sua aplicação. Vitoria, ES; Incaper, 2012.

RAIJ, B. van. Fertilidade do solo e adubação. São Paulo: Agronômica Ceres; Piracicaba: Potafos, 1991.

RAO, I.M.; AYARZA, M.A. \& GARCIA, R. Adaptive attributes of tropical forage species to acid soils I. Differences in plant growth, nutrient acquisition and nutrient utilization among C4 grasses and C3 legumes. Journal of Plant Nutrition, 18, p. 2135-2155, 1995.

RIBEIRO, M. A.V.; Novais, R. F.; FAQUIN, V.; FERREIRA, M. M.; FURTINI NETO, A. E.; LIMA, J. M. e VILLANI, E. M. A. Resposta da soja e do eucalipto ao aumento da densidade do solo e a doses de fósforo. Revista Brasileira de Ciência do Solo, 34, p. 1157 1164, 2010.

ROSSI, C., MONTEIRO, F.A. Doses de fósforo, épocas de coleta e o crescimento e diagnose nutricional nos capins Braquiária e colonião. Scientia Agrícola, 56, n. 4, p. 1101-1110, 1999. 
ROZANE, D. E.; PRADO, R. de M.; FRANCO, C. F.; NATALE, W. Eficiência de absorção, transporte e utilização de macronutrientes por porta-enxertos de caramboleira, cultivados em soluções nutritivas. Ciência e Agrotecnologia, 31, n. 4, p. 1020-1026, 2007.

SANTOS, I. P. A. Resposta a fósforo, micorriza e nitrogênio de Braquiarão e amendoim forrageiro consorciados.1999. 158 f. Dissertação (Mestrado em Zootecnia) - Universidade Federal de Lavras, Lavras/MG, 1999.

SANTOS, H. Q. et al. Níveis críticos de fósforo no solo e na planta para gramíneas forrageiras tropicais,em diferentes idades. Revista Brasileira Ciência Solo, 26, p.173-182, 2002.

SANTOS-FILHO, B. G.; PANTOJA, M. J. R.; BATISTA, T. F. C.; TAVARES, A. E. B., RIBEIRO, R. C.; PINHEIRO, H. A. Comportamento Nutricional de Espécies Arbóreas Utilizadas no Reflorestamento de Áreas Degradadas Sob o Impacto da Exploração Petrolífera na Região de Urucu, Município de Coari, AM. Revista Brasileira de Biociências, Porto Alegre, v. 5, supl. 2, p. 1134-1136, 2007.

SIDDIQI, M.Y.; GLASS, A.D.M. Utilization index: a modified approach to the estimation and comparison of nutriente efficiency in plants. Journal of Plant Nutrition, New York, v.4, n.3, p. 289-302, 1981. Disponivel em:

https://www.alice.cnptia.embrapa.br/alice/bitstream/doc/205149/1/006.pdf. Acessado em: 02 de março de 2019.

SILVA, J.E.P. Parâmetro produtivos e atividades de fosfatase ácida em três gramíneas forrageiras cultivadas com doses de fosforo. 1996. $81 \mathrm{f}$. Tese (Mestrado em Agronomia) Escola Superior de Agricultura "Luiz de Queiroz" - Universidade de São Paulo, Piracicaba, 1996.

SWIADER, J.M.; CHYAN, Y.; FREIJI, F.G. Genotypic differences in nitrate uptake and utilization efficiency in pumpkin hybrids. Journal of Plant Nutrition, New York, v.17, n.10, p. 1687 - 1699, 1994.

ZIMMER, A. H. \& CORREA, E. S. A pecuária nacional, uma pecuária de pasto? In: ENCONTRO SOBRE RECUPERAÇÃO DE PASTAGENS, 1, 1993, Nova Odessa. Anais... Nova Odessa, Instituto de Zootecnia, 1993. p.1-26. 